\title{
ENSAIO INTRODUTÓRIO SOBRE MINERACOLOGIA: PROPOSTA DE FOMENTAÇÃO DA REFLEXÃO E DISCUSSÃO DA MINERAÇÃO PELO VIÉS DA AGROECOLOGIA
}

Nome do Autor (a) Principal

\section{Carolina Braz Góes}

Nome (s) do Orientador (a) (s)

Hildebrando Herman

Instituição ou Empresa

Universidade de Campinas - UNICAMP

E-mail de contato

carolina.braz.goes@gmail.com

Palavras-chave

Mineração, sustentabilidade, agroecologia, pequenos mineradores, visão holística, mineracologia

\subsection{INTRODUÇÃO}

Atualmente, conflitos relacionados a questões socioambientais são os de maior quantidade no mundo (NUNES, 2012). Demasiadas são as externalidades negativas que acontecem por causa da exploração mineral. Tais aspectos são apontados no presente artigo e é fomentada uma nova perspectiva sobre o assunto através de quebra de paradigma, reconstrução de valores e propostas em relação a mineração. A educação ambiental comenta a impossibilidade de compreender os problemas sócio-econômicos dentro do paradigma cartesiano e propõe o viés da complexidade (VIÉGAS, 2005). Nesse contexto de educação ambiental acontece resgate dos saberes populares (MARTINS, 2007), dessa forma também é proposto 0 
resgate de conhecimentos dos pequenos mineradores e busca por um mundo equitativo, assim como o viés da agroecologia, que propõe visão sistêmica, descrita por CAPRA (2009) como a visão onde todos os elementos estão conectados e tem relações interdependentes entre si, como uma teia e também pertencimento endógeno, descrito por CARPORAL (2009) por "aquilo que nasce de dentro e soma o que vem de fora, mediante seus princípios".

\subsection{JUSTIFICATIVA}

O artigo é justificado pela grande quantidade e agressividade de conflitos entre povos e empresas mineradoras, entre natureza e tecnocracia. $O$ cenário é de opressões e agressões, quase sempre vinculadas às empresas com grande poder econômico. Essas empresas estão usualmente em busca de mais lucro, o que soma ao cenário: desapropriações obrigatórias, injustiças, contaminações, poluições, descasos, desvalorização da vida em geral. Dentre esses e tantos outros conflitos relacionados aos recursos naturais, e na mineração, vê-se a necessidade de abordar tais questões para se fazer fomentar mais os questionamentos e reflexões sobre: ética, moral, modelo econômico imposto, cultura, direito, paradigmas, resistência, valores, princípios, no âmbito acadêmico, social, governamental e empresarial.

\subsection{DESENVOLVIMENTO}

A revisão bibliográfica relacionou as problemáticas socioambientais da agricultura convencional com as mesmas problemáticas da mineração convencional.

Tem-se a questão da obsolescência planejada, resíduos recicláveis e reutilizáveis que não descartados junto com resíduos em geral e não são reaproveitados, energia, vínculo com governos, recursos naturais extraídos para fins não necessários, entre esses e muitos outros fatores que interferem na mineração de larga escala como o consumismo impulsionado e desenfreado, a cultura contemporânea (cultura do descartável), e a inversão de valores na relação homem e homem, como a indiferença ao trabalho de caráter neo escravo e a indiferença 
com relação a poluição de solos, água, poluição sonora ou atmosférica, além da larga geração de resíduos, sejam sólidos, líquidos ou atmosféricos, transformação da paisagem, esgotamento dos recursos naturais locais, interferência negativa em escala micro ou macro em todos aspectos ambientais e socioambientais.

Porém tradicionalmente os recursos eram explorados a partir da necessidade e o método seguia preceitos éticos, visando cuidados com a Terra, partindo do entendimento que todos os seres vivos, são dependentes dela e interdependentes entre si. Na revolução industrial houve uma mudança de pensamento coletivo, seguida da brusca mudança de comportamento. Sendo assim, o conhecimento científico convencional erodiu os conhecimentos locais, impôs a homogeneização dos aspectos socioculturais, tais aspectos foram ocidentalizados e vinculados a modernização. (Guzmán, 1999) apud (Carporal, 2001)

A agroecologia não é entendida como um modelo ecológico de produção agrícola, é mais complexo e profundo. Segundo MORIN (1999) apud VIÉGAS (2005): "A complexidade não é um conceito, mas uma forma de enxergarmos a realidade, devido ao conhecimento incompleto que temos da realidade".

Percebe-se então que agroecologia ultrapassa a esfera da agricultura. Seu conceito pode ser expandido e adaptado em outros meios de exploração de recursos naturais, além da agricultura e pecuária, onde é originalmente proposto.

Os primeiros direitos relacionados a mineração surgiram a partir dos costumes, que eram reconhecidos pela sociedade local como legítimos e depois incorporados a legislação da época, retratando as tradições jurídicas populares que já demonstravam conflitos com as ciência jurídica letrada. (REZENDE, 2013)

Comprova-se que o conhecimento científico e o conhecimento tradicional sempre coexistiu, por mais que de maneira conflituosa, principalmente por terem interesses opostos.

\subsection{METODOLOGIA}

Como metodologia de trabalho utilizou-se a revisão bibliográfica de artigos científicos, contos literários relacionados às tradições, técnicas, costumes e cultura do pequeno minerador, documentários audiovisuais, diálogo informal com 
integrantes de movimento sociais contra injustiças entre natureza, sociedade e grandes empresas mineradoras. $O$ desenvolvimento da proposta de mudança de perspectiva e quebra de paradigma é de modo experimental e teórico, sendo assim, tem objetivo de abordar questões de recursos e ciências naturais, ecológicas, tecnológicas e sociais, no âmbito da reflexão, buscando transformar a óptica acerca de tais assuntos, trazendo sua complexidade para ser rediscutida pela sociedade.

\subsection{RESULTADOS E CONCLUSÃO}

COSTA (2009) Comenta o quanto os contornos da vida econômica, em torno da extração mineral, influenciam nas formas de pensar, de sentir e de sonhar de seus envolvidos.

Essa constatação pode ser ampliada para todas as esferas. Assim como a agroecologia, esse artigo propõe que o estudo mais aprofundado da mineracologia possa resgatar culturas, buscar um mundo mais justo e equilibrado, causar menos degradação ambiental e poluição, ou mesmo, e ser um de muitos instrumentos de resistência.

Sobre a confusão que relaciona valores e o capital MORE (1516) apud COSTA (2009), comenta:

\footnotetext{
"Muitos se espantam em saber que o ouro, em si mesmo um bem tão inútil, goze de tamanha estima em toda parte, que mesmo os homens para quem foi feito e pelos quais o valor lhe é atribuído sejam concebidos como dotados de menor valor que o próprio ouro."
}

Pela questão ambiental atual far-se-á necessário a mudança na perspectiva da mineração. Se não for por abordagens aqui comentadas, será pela limitação dos recursos naturais não renováveis, por conflitos devastadores, pela falta de água, energia ou de outros recursos utilizados na mineração em geral, conclui-se então a importância da fomentação da discussão do viés construído e imposto pela mineração convencional ou empresarial.

\subsection{REFERÊNCIAS}


CAPANEMA, Carolina Marotta. "A natureza no foco das relações de poder em Mariana". Belo Horizonte: Fino Traço, 2013.

CAPORAL, Francisco Roberto, José Antônio Costabeber, Gervásio Paulus. "Agroecologia como matriz disciplinar para um novo paradigma de desenvolvimento rural." Congresso Brasileiro de Agroecologia. Vol. 3. 2005.

CAPRA, Fritjof; EICHEMBERG, Newton Roberval. A teia da vida: uma nova compreensão científica dos sistemas vivos. Editora Cultrix, 2006

COSTA, Luciano Rodrigues. "Os garimpos clandestinos de ouro em Minas: tradição e mudança." Revista História \& Perspectivas 1.3637 (2009).

ECO dos Carajás Observatório Socioambiental do sudeste paraense. "Minerando Conflitos". Produção audiovisual Nacional.. Disponível em https://www.youtube.com/watch?v=nvSrlQbHLdc\#t=16 Acessado em 10 de Dezembro de 2014

EHLERS, E.M. O que se entende por agricultura sustentável? São Paulo USP-FEA,1994. 161p. Dissertação Mestrado.

DANNORITZER, Cosima. "A História Secreta da Obsolescência Planejada." Arte FranceTelevisión de Catalunya. Disponível em: www. youtube. com/watch. Acessado em 10 de Setembro de 2014.

FILHO, Saulo Rodrigues; LIMA, Maria Helena Rocha; SIROTHEAU, Gloria Janaína; SCHNELLRATH, Jurgen; BOAS, Roberto C. Villas. "Garimpo e Inclusão Social no Brasil: dois estudos de caso". Centro de Tecnologia Mineral, Rio de Janeiro, RJ. 2010

FURTADO. C. "Em busca de um novo modelo; reflexões sobre a crise contemporânea". São Paulo, Paz e Terra, 2002.

MARTINS, Marcos Lobato. "Mineração, identidade garimpeira e meio ambiente: os conflitos em torno da extração de diamantes no Alto Jequitinhonha, 1989 - 1995". Associação Nacional de História - ANPUH XXIV Simpósio Nacional de História. 2007

MELO, Geórgia Karênia Rodrigues Martins Marsicano, N. E. T. O. de DANTAS, and Kettrin Farias Bem José MARACAJÁ. "Histórico evolutivo legal dos recursos hídricos no Brasil: uma análise da legislação sobre a gestão dos recursos hídricos a partir da história ambiental." 2010

NUNES, Edilon Mendes, and Loreley Gomes Garcia. "Sociedade e natureza: conflito territorial de poluição industrial da bacia do rio gramame-mumbaba-pb." Sociedade \& Natureza 24.2 (2012): 255-265.

QUEIROZ dos Santos, Everaldo. "Serra Pelada - A Lenda da Montanha de Ouro" 2013. Documentário audiovisual nacional. Disponível em https://www.youtube.com/watch?v=pUJzpgAZ7Sw Acessado em 25 de Novembro de 2014.

RENGER, Friedrich E. "Direito Mineral e Mineração no Códice Costa Matoso (1752)". Varia História. Belo Horizonte, n. 21, jul. 1999, p. 159 
REZENDE, Dejanira Ferreira de. Mineração nos morros das Minas Gerais [manuscrito]: conflitos sociais e o estilo dos pequenos exploradores (1711-1779). Dissertação de Mestrado. Universidade Federal de Ouro Preto (UFOP). 2013

SILVA, Ana Caroline Dias; SILVA, Juliana Dal Bello Ferreira da. "Diálogo entre Educação Ambiental e Tecnologias Sociais: Acompanhamento de um processo de Tecnologia Social em uma área rural”. 2014. Trabalho de Conclusão de Curso. Universidade Estadual de Campinas (UNICAMP), Campinas. 2014.

SILVEIRA, MA da, and José Maria Gusman Ferraz. "Sustentabilidade, pesquisa interdisciplinar e agricultura familiar: uma discussão crítica." EMBRAPA MEIO AMBIENTE. Jaguariúna, SP (2003).

STAMPEDE Productions. "The Coconut Revolution". 2000. Documentário audiovisual britânico. Disponível em https://www.youtube.com/watch?v=LDpvxQe Jhg Acessado em 20 de Novembro de 2014

VIÉGAS, Aline, \& M. GUIMARÃES. "Complexidade: uma palavra com muitos sentidos." Encontros e caminhos: formação de educadoras (es) ambientais e coletivos educadores. Brasília: Ministério do Meio Ambiente (2005): 71-82. 